The Camivalesque Practice of Language Writing in the Groteque Body of I Don't Hove Any Paper

Previous: Snickers and Sex: Bawdy Humour in Three of Martial's Epigrams by Brandon Moores

Next: She's Such a Tease: The Feminine as Burlesque Performance in Margaret Atwood's The Edible Woman by Katherine Ovens

\title{
The Carnivalesque Practice of Language Writing in the Grotesque Body of I Don't Have Any Paper
}

David Milman

Pivot is published through Open Journal Systems (OJS) at York University 
There is a similarity between the rhetorical strategies of Language Writing and the rhetorical strategies attributed to carnivalesque texts by Mikhail Bakhtin. However, the aesthetic differences between standard uses of the carnivalesque and grotesque realism may, at first, obfuscate these similarities in rhetorical strategy. While the aesthetic of these two forms of writing is certainly not identical, there are enough allegorically and rhetorically parallel The Carnivalesque Practice elements to state that a form of the carnivalesque and grotesque is at work in Language Writing. To prove as much I will summarize Mikhail

Bakhtin's articulation of

carnival and grotesque realism and then draw lines of similarity between that articulation and the strategies of Language Writing expressed by Bruce Andrews and Steve McCaffery. In the process I will bolster my argument with reference to textual examples, taken from Bruce Andrews's I Don't Have Any Paper So Shut Up (or, Social Romanticism), which exemplify these parallels in operation.

Bakhtin's carnivalesque mode of literature is essentially a form that utilizes medieval carnival folk humour. The most important aspect of that medieval folk humour is the rhetoric that informs it. For example, Bakhtin argues that the carnival cannot set itself apart from the crowd via the aesthetic of footlights, as that would "destroy a carnival" (Bakhtin 7). What is important is not the aesthetic lack of footlights, however, but the reason why they cannot exist: "everyone participates because its very idea embraces all the people" (Bakhtin 7). A carnival operates on the principle of inclusion.

This form relies on a sense of the public sphere. The carnivalesque employs an aesthetic form that Bakhtin describes as "grotesque 
realism." Grotesque realism depicts "images of the human body ... [in which] food, drink, defecation, and sexual life, plays a predominant role" (Bakhtin 18). The body here, however, is "not ... [representative of] the biological individual, not ... [representative of] the bourgeois ego" (Bakhtin 19). The "body and bodily life have here a cosmic and at the same time an all-people's character. ... a people who are continually growing and renewed. This is why all that is bodily becomes grandiose, exaggerated, immeasurable" (Bakhtin 19). This carnival parody of the body creates carnival laughter: "Carnival laughter is the laughter of all the people ... it is universal in scope; it is directed at all and everyone, including the carnival's participants" (Bakhtin 10).

This all-encompassing laughter of the public sphere is a form of degradation: "Laughter degrades and materializes" (Bakhtin 20). Bakhtin states that the "essential principle of grotesque realism is degradation" (Bakhtin 19). By degradation he means an attack upon abstract, spiritual idealism that instantiates it in an embodied earthly sphere (Bakhtin 19-20). This is because the carnivalesque is designed to be "hostile to all that [is] immortalized and completed" (Bakhtin 10), in the sense of destroying the boundaries that separate concepts such as the ideal form from the reality of embodied instantiations.

It is important to note, however, that this aspect of the folk humour employed by the carnivalesque is not designed only to destroy. Destroying this boundary through degradation is "to concern oneself with the lower stratum of the body, the life of the belly and the reproductive organs" (Bakhtin 21). As a result it contains a regenerative aspect (Bakhtin 21). The purpose is not to hurl down the ideal form "into the void of non-existence, into absolute destruction, but to hurl it down to the reproductive lower stratum, the zone in which conception and a new birth take place" (Bakhtin 21); the carnivalesque is not only hostile to all that is immortalized and completed, but it reconstructs everything that is immortalized and completed into something new, "something more 
and better" (Bakhtin 21). The text uses images that are "ambivalent and contradictory" (Bakhtin 25) to destroy and produce, to cause death in order to instigate a birth.

While this form is based on the public sphere, it is important to note that it was not originally based upon official space or official celebration. As Bakhtin says, "the official feasts of the Middle Ages, whether ecclesiastic, feudal, or sponsored by the state, did not lead the people out of the existing world order and created no second life. On the contrary, they sanctioned the existing pattern of things and reinforced it" (Bakhtin 9). Officially sanctioned spaces, and the feasts that take place within them, are expressions of the status quo. Bakhtin notes that the carnival is "opposed to the official feast" (Bakhtin 10) and does not express the status quo; rather, the carnival includes the "utopian ideal" (Bakhtin 10). Darko Suvin describes the "first approximation to identifying the thematic nucleus of the utopian genre" (Suvin 45) as "[t]he imaginary community ... in which human relations are organized more perfectly" (Suvin 45, italicized in the original) than our own. Bakhtin's inclusion of a utopian ideal in the carnivalesque would indicate that it is driven by the desire for a more perfect form of organization. This desire, this ideal, always exists in tension with the status quo. The status quo desires to be immortalized and completed, static, for that which is statically immortalized and completed need not fear replacement with something better, something else, a form of organization that is not the status quo. Of course, the carnivalesque did serve to defuse social unrest by the lower classes, but it did so by offering a temporary "suspension of all hierarchical rank, privileges, norms, and prohibitions" (Bakhtin 10), in effect defusing social unrest by providing a respite from the very factors which create it.

With time the notion of the grotesque has undergone a certain metamorphosis. It has moved away from the rhetoric of medieval carnival folk humour. During the Renaissance the perception of the body underwent a drastic revision: "the body was first of all a 
strictly completed, finished product. Furthermore, it was isolated, alone, fenced off from all other bodies" (Bakhtin 28). The abject protrusions and excretions that informed carnival folk humor were glossed over. The grotesque, likewise, lost its ability to represent a total public sphere. Just as each body became fenced off from all other bodies so too did the concept of cognitive space. In the era of Romanticism, "the grotesque genre ... [underwent] a radically transformed meaning. It became the expression of subjective, individualistic world outlook very different from the carnival folk concept of previous ages" (Bakhtin 36). The carnival became a space of personal isolation.

From that point on, Bakhtin reads laughter as a thing steadily robbed of its positive capabilities. By the time Bakhtin analyses modernist laughter, he claims that laughter came to have "a solely negative character and is deprived of regenerating ambivalence" (Bakhtin 21). However, I would argue that there is a postmodernist genre that employs a form of carnivalesque, which recreates the public sphere, which ambivalently destroys and produces with simultaneous expression, and thus regains its regenerative capability.

Much of the philosophy behind Language Poetry, or Language Writing, bears a remarkable similarity to certain aspects of Bakhtin's articulation of monoglossia and heteroglossia. Monoglossia refers to "a centripetal movement towards 'a unitary master language' that 'gives expression to forces working toward a concrete verbal and ideological unification and centralization'" (Evans 66). Heteroglossia, on the other hand, "is a centrifugal movement towards the stratification of language into a plethora of ... diversified dialects and discourses" (Evans 66). The conflict between these two tendencies is, "[i]n Bakhtin's view, the fundamental event of the linguistic community" (Evans 66).

We can understand monoglossia as a transparent use of language in which the relationship between signifier and signified is bound in 
the totalizing force of grammar. After all, as Steve McCaffery states:

[G]rammar extends a law of value to new objects by a process of totalization, reducing the free play of the fragments to the status of delimited, organizing parts within an intended larger whole. Signifiers appear and are then subordinately organized into these larger units whose culmination is a meaning which is then invested in a further aggregation. Grammar's law is a combinatory, totalizing logic that excludes at all costs any fragmentary life. (151)

Thus, grammatically "correct" language can be understood as inherently acting as a tool of power for the monoglossic tendencies of a linguistic community. Such language is always an example of centripetal movement towards a unitary master language, a totalizing logic that excludes, at all costs, fragmentary life and its dialects.

Likewise, Language Writing is an assault on this monoglossic tool, a heteroglossic assault upon grammar itself:

Language Writing resists reduction to a monological message, offering instead an organized surface of signifiers whose signified are undetermined. There is a primacy lent to readership as a productive engagement with a text in order to generate local pockets of meaning as semantic eruptions or events that do not accumulate into aggregated masses. (McCaffery 149)

The tension between grammar and Language Writing is the site of battle between monoglossia and heteroglossia. I would even go so far as to state that Language Writing can be described as a hallmark of heteroglossic culture. Considering that "the tradition of 'Carnival,' its mixing and inverting of identities ... [has also been named] the hallmark of heteroglossic culture" (Evans 67), it should not come as a surprise that I believe that the postmodernist genre that employs a form of carnivalesque, which recreates the public 
sphere, which ambivalently destroys and produces with simultaneous expression, and thus regains its regenerative capability, is Language Writing.

As has already been stated, carnival does not know footlights. Carnival is not a spectacle that is seen, but rather is an activity in which one engages. Thus, at first, it may seem that certain condemnations of avant-garde poetry disqualify Language Writing as a form of the carnivalesque: "'Language poets' like [Bruce Andrews] are often charged with elitism and hermeticism"' (Perloff qtd. in Andrews, Paradise \& Method 76) due to the way their radical linguistic and visual experimentation can arguably conceal meaning. For example, Glyn Maxwell condemned Language Writing for being an example of "complete and deliberate impenetrability" (qtd. in Perloff 171). Simply because something is condemned, however, does not indicate that it knows footlights or is a spectacle which is merely seen. Indeed, according to Bakhtin, the first attempts to theoretically analyse the grotesque condemned its practice: "Vetruvius condemned the grotesque from the classical standpoint as a gross violation of natural forms and proportions. Vasari expressed a similar point of view which prevailed for a long time" (Bakhtin 33). I believe that these condemnations of Language Writing as "arch," "elitist," or "hermetic" on the grounds of its unconventional grammatical from are very similar to Vetruvius and Vasari's condemnations of the grotesque as a violation of natural bodily forms.

Language Writing is (in the grand scope of things) a relatively recent practice, and it is a practice that is directly contrary to the "natural form" instituted by grammar. Bruce Andrews states that "Poetry is an art of constitution. ... Politics is a ceaseless process of constitution" (Paradise \& Method 30; original emphasis). In terms of politics, Andrews states:

Overt conflict does not make up the entire field. There are constant compromises and acquiescence ... that lead to different forms of hegemony. ... It is like a policy - a policy 
over the body. Socialization. Politics as the fight for norms, over the body. Writing is thus brought close to politics, by the parallels of similar commitments and similar weight. (Paradise \& Method 30; original emphasis)

Seen in this light, we can consider the body of any text to be an allegory for the community of its readers and all their potential interpretations, much like the body in the carnivalesque is an allegory for the public sphere. The struggle between the monoglossic and heteroglossic elements of this linguistic community is played out over the body of text. Grammar acts like a hegemonic policy attempting to institutionalize the monological message, the norm, the "natural form" of writing. But Language Writing, through its obfuscation of meaning behind undetermined signifiers, acts as an "active politics and politicization of value, of the body - in the sense that you refuse to allow either the active construction of value or meaning and the body to become, simply, objects of administration" (Andrews, Paradise \& Method 30). An inherent necessity of this process requires the text to transgress the "natural form" of text (as defined by the policies of grammar). The use of undetermined signifiers is the process by which these texts perform this transgressive activity. Thus, to criticize these texts for that process is to do little more than condemn the grotesque as a violation of the natural form.

But these texts do more than just violate the natural form. In the process of this violation, they break down the barrier between the spectacle and the spectator, remove the footlights, and force their audience to participate with the text. Let us examine the following lines from the poem "Animal Dicks in Bed" by Bruce Andrews:

Arsenio, fuck me! Torn dread low gloss

gives a sweat, this pen writes, what did I say? Really bankrupt hungry classics, rouge dinge sorties into 'mama klieg light' dental care begins at midnight dipole self-abuse... (I Don't Have Any Paper 18) 
The lack of grammatical policy here certainly conceals meaning behind radical linguistic and visual experimentation; these lines of poetry resist a monological message, a "natural form." The signifiers (such as mama klieg light) have no predetermined signifieds. As a result the readership must productively engage in the text in a Barthesian sense: "The productive return of the reader can only take effect through the theoretical presupposition of a need to produce" (McCaffery 27; original emphasis). There is no inherent meaning here. The reader needs to produce, to "understand each word in its duplicity" (Barthes 59). This results in a direct dialogue between the reader (or spectator) and the text (or spectacle). The text forces every reader to participate. Even to decide that the text lacks any meaning, that the text is intellectually elitist, is to posit a personal interpretation of meaning on the text, and thus to participate with it.

The carnivalesque employs laughter, the laughter of all the people, directed at everyone including the carnival's participants (Bakhtin 10). We can essentially state that the carnivalesque employs grotesque bodies and the abject in spectacles devoid of footlights to represent everyone and everything while simultaneously directing its rhetoric at everyone and everything. Similarly, the very act of forcing everyone to participate with a text is a totally inclusive process. But I would like to go even further and state that Language Writing reinstates the public sphere, giving a rebirth to certain rhetorical strategies that slowly lost their place amidst the grotesque due to the steady increase in cognitive subjectivity that entered into writing after the medieval time period.

To prove as much I will begin by examining a few lines from the poem "Autocracy Managed by Midgets." In that poem Andrews writes:

Autocracy managed by midgets - change the mind, eliminate its cause - set up

cancel to mush lube job on my assumptions, improving capital will be dignity through artifice pride is sorry state - jury 
sauna, centipede family of lust without wings. (I Don't Have Any Paper 30)

What information do these lines convey? What is this autocracy managed by midgets? What is a "mush lube job?" How does one "set up cancel to" one? What is a "jury sauna," and how does it relate to a "centipede family of lust without wings?" There is certainly no essential signified to which the signifiers used point towards. The lack of standard grammar, and the presence of a paratactic relationship between units of signifiers, ensures that. This does not mean, however, that the lines lack any form of information. In The Human Use of Human Beings Norbert Wiener writes, "it is possible to interpret information carried by a message as essentially the negative of its entropy, and the negative logarithm of its probability. That is, the more probable the message, the less information it gives" (21). David Porush neatly sums up a key point about how information operates, as a result, as follows:

Information is simply a measure of the probability that a given signal or element will be selected from among a set of differentiated elements, a set of alternatives. Therefore, information is proportional to the amount of variety (entropy) in the original set and has an accompanying sign change. ... The more random the assortment of potential signs or elements in a code, the more information a choice from among those alternatives communicates. (57; original emphasis)

Thus, as the code of grammar in "Autocracy Managed by Midgets" does not restrict the choice of which signifier must be used in any given location within a body of text, as the choice of alternatives is greatly increased, each actual word includes a larger quantity of information (according to information theory). As someone "[w]ellinformed of developments in information theory as well as systems theory" (Ma 176), Andrews would be familiar with such concepts. 
Admittedly, "information is quantified in proportion to its variety only, but humans rely upon redundancy in order to perceive meaningful patterns in their communication with the world and each other" (Porush 59). Or, as Wiener explains it, "[m]essages are themselves a form of pattern and organization" (21). This is something Andrews was familiar with as well, as he writes: "THE COMMUNICATIONAL SUCCESS OF A MESSAGE IS IN DIRECT PROPORTION TO THE AMOUNT OF REDUNDANCY IT CONTAINS" (Andrews qtd. in Ma 176). The question, of course, is why should this redundancy, or meaningful pattern, be located in the text itself? "Autocracy Managed by Midgets" is allowed to possess a larger quantity of information, as it is a multiplicity of readers and not a singular author who traces redundancies and meaningful patterns between the text's signifiers; meaning is dictated by the perspective of one's relation to the text instead of the text itself. Thus, "Autocracy Managed by Midgets" theoretically includes a superabundance of meaning via a paratactic relationship of signifiers.

That is exactly the argument proposed by Andrews in his essay "Total Equals What: Poetics \& Praxis." Further, Andrews also calls "attention to the possibility ... that ... totality isn't just a negative restrictive thing, or some deterministic program. It's also something that's reproduced by action within the system and, at the same time, it becomes a resource or a medium that can be drawn upon" (Andrews, Paradise \& Method 38-39). The totality that Andrews describes is not the "combinatory, totalizing logic" (McCaffery 151) of grammar discussed above. It is not the subjective perspective which is imposed by grammar, and then used as a stand-in for every reader's assumed perspective on the text. In this sense, "[i]t's contextualizing and reshaping and contesting ... [that] I'm calling totalizing. Beyond form's maximizing of act, this would be a parallel maximizing of context, or of paradigm" (Andrews, Paradise \& Method 41; original emphasis). Specifically, this would be the totalizing that occurs when a paratactic relationship of signifiers allows for a superabundance of 
meaning due to the nearly infinite number of interpretations any single reader can bring to a text. As Language Writing removes the footlights and transforms the audience into an aspect of the text itself, this means that every possible interpretation is valid, and this "kind of writing might then seem like a part of public life-in the sense of the public sphere-an access point to totality. ... [This] totalizing poetic practice involves a kind of social denormalizing-at work on the structure of the sign but also on these larger shapes of meaning -that would allow for a revitalizing of the idea of a public sphere" (Andrews, Paradise \& Method 48; original emphasis). As such, the above stanza from "Autocracy Managed by Midgets" can be seen as representing the public sphere in much the same way that the body once did in grotesque realism. Word combinations such as "flagellation - we're suck" (Andrews, I Don't Have Any Paper 30) act like the "grandiose, exaggerated, immeasurable" (Bakhtin 19) limbs of the grotesque body which "is contained not in the biological individual, not in the bourgeois ego, but in the people, a people who are continually growing" (Bakhtin 19).

The true carnivalesque depicts such continually growing bodies because it is "hostile to all that [is] immortalized and completed" (Bakhtin 10). Language Writing, by definition, is also hostile to everything that is immortalized and completed. Grammar is the method by which language is made transparent, by which the signified, which a signifier points to, is immortalized and completed via chains of signification: "As a transcendent law, grammar acts as a mechanism that regulates the free circulation of meaning, organizing the fragmentary and local into compound, totalized wholes" (McCaffery 151). When one examines any of the poems in a text such as I Don't Have Any Paper, one must notice that grammar is not allowed to perform this function. Any of my above examples can prove this point, but to keep my sampling of this text varied I will instead look at the first lines of "Breed Your Followers":

Breed your followers - imperial hot plates with pleats, slap that kid with a union plan. Hotel lips is like hotel butter, 
blunder rather

invest in loyalty

that danger excuses your brain. Life is just another ointment.

(Andrews, I Don't Have Any Paper 45)

Whatever followers these signifiers may breed, they are not signifieds attached by chains of signification. Sometimes there are lines that almost seem to breed meaning; for example: "Breed your followers" (Andrews 45). But this meaning is undone with phrases such as "Hotel lips is like hotel butter" (Andrews 45), which mean nothing to a reader unless they produce their own meaning. As Andrews would say, "[t]he very structure of the sign is violated, deliberately liberating energy flows trapped within this system of relations" (Andrews, Paradise \& Method 25).

Of course, the carnivalesque is not merely hostile, it is also regenerative: "[it] denies, but it revives and renews at the same time" (Bakhtin 11). Carnivalesque bodies are not only continually growing, they are also renewed (Bakhtin 19). Similarly, Language Writing liberates energy flows for a purpose that is not purely destructive. The purpose of this practice is ultimately the return of a productive reader, it is "the incessant ( $\&$ potential) production of meaning $\&$ value. ... Not passively. ... active-back $\&$ forth: ... writing \& reading" (Andrews, Paradise \& Method 18; original emphasis). Indeed, as I have shown, these texts can even be read as recreating the public sphere. So, "[s]omething is lost but something is gained" (Andrews 6); Language Writing texts "bury, to sow, and to kill simultaneously, in order to bring forth something more and better" (Bakhtin 21), just like the carnivalesque. Just as the grotesque body is "ambivalent and contradictory" (Bakhtin 25), a simultaneous icon of destruction and creation, so too do signs in Language Writing become "decidedly ambivalent, a pressure point produced by the confluence of [the] conflictual drives" (McCaffery 155) of destruction and creation. The textual body of "Breed Your Followers" becomes a body that is simultaneously a rotting corpse and birthing mother. 
The philosophy of Language Writing, and its practice within such texts as I Don't Have Any Paper, works on a very similar rhetorical principle to carnivalesque texts. Such texts are not the natural form, or "official feast," but rather the avant-garde. Their very principle is all inclusive. They are not a spectacle contained by footlights, but rather a spectacle of which a spectator is a part; these texts require (and ensure, more or less) productive participation from both writer and reader. Their rhetoric is directed at everyone, for everyone makes use of language, and the potential perspective of meanings present in any text is infinitely large. Language Texts thus can be read as an "access point to totality" (Andrews, Paradise \& Method 48), the recreation of a public sphere, which then simultaneously becomes an allegory for the public sphere. Likewise, these texts are hostile to everything that is immortalized and complete. They abolish conventional chains of signification and destroy inherent meaning. In the process, however, they recreate meaning through a potentially infinite number of meanings that must be produced by a reader. This goal is perceived, by the Language poets, as utopian. Their work is proposed as an "antidote ... to what they describe as the imprisonment of American poetry within a poetics of the private self" (Shetley 136).

This process is not just linguistic, it is also political. The poetry has been described as containing an aesthetic that is underpinned by an "explicitly political character" (Shetley 138). Part of this comes from the fact that "the Language writers generally announce themselves as Marxist radicals" (Shetley 138). Certainly, in the heteroglossic code of a poem like "Autocracy Managed by Midgets" there is a Marxist component. The poem refers to a "House of Loot" (Andrews, I Don't Have Any Paper 30), which could signify a center of capitalism. The poem also refers to a "class struggle" (Andrews 30), which is one of the central defining pillars of Marxist discourse. Statements such as "improving capital / will be dignity through artifice pride is sorry state" (Andrews 30 ) can be interpreted as insulting the type of dignity and pride produced by improving 
capital (wealth) as an artificial and "sorry state." Ultimately, however, the poem's political power rests not in its chains of significations but rather in the ambiguous uncertainty as to their actual meanings.

Vernon Shetley summarizes the scenario by quoting Jerome McGann's statement: "Narrativity is an especially problematic feature of discourse ... because its structures lay down 'stories' which serve to limit and order the field of experience, in particular the field of social and historical experience. Narrativity is ... an inherently conservative feature of discourse" (140). Shetley then explains, "If narrative is inherently conservative, then the abandonment or sabotaging of narrative challenges the foundations of the existing order" (140). The politically revolutionary quality of an "Autocracy Managed by Midgets" is a lack of a preordained syntactic pattern. That lack bankrupts any clear sense of narrativity and challenges the foundations of the existing (capitalist) social order which codes those syntactic patterns. This is the quality of Andrews's work which John Wrighton reads as an attack against the "'harshness and universal power' of a language made to justify the atrocities of 'near-genocidal brutality"' (148) by the Nixon administration.

It is by that method that Language Writing can be said to "draw an analogy, throughout, between language and society" (Andrews, Paradise \& Method 33). Like the carnivalesque, such texts are driven by a utopian desire. Language Writing possesses "a utopian force [that has] only begun to be revealed" (Andrews 13). Of course, like Shetley, one can question the efficacy of that utopian force. But then, the same can be said to be true of the utopian power once possessed by the carnivalesque. It did not, after all, abolish the hierarchy that caused social unrest in any permanent manner. The carnivalesque merely defused the social unrest of the lower classes via a respite from that unrest's root causes. In any case, I leave the question of the efficacy of Language Writing's technique to other papers, as an analysis of that efficacy is 
somewhat outside of the purview of this article. For the purpose of this article, I am solely interested in pointing out the utopian impetus present in I Don't Have Any Paper, no matter what its efficacy.

Despite all these similarities, however, calling I Don't Have Any Paper an example of a contemporary carnivalesque text, or claiming that it is grotesque, would be somewhat confusing. It does not fit into Bakhtin's aesthetic of the carnivalesque or grotesque realism. Bakhtin describes that aesthetic as being composed of three distinct forms: ritual spectacles, comic verbal compositions, and various genres of billingsgate (Bakhtin 5). Ritual spectacles are forms of "carnival pageants, [and/or] comic shows of the marketplace" (Bakhtin 5). Obviously, I Don't Have Any Paper does not qualify as either. Only in its lack of "footlights," its instance that a reader activity participate in the process of determining a signifier, does the text share anything in common with these ritual spectacles. That is to say, its aesthetic is informed by a similar rhetoric, but the aesthetic is not the same.

Comic compositions are types of "parodies both oral and written" (Bakhtin 5). Likewise, calling I Don't Have Any Paper a parody is difficult. For something to be parodic it must create a clear chain of signification. That chain causes the signified to become ridiculous and comic, but it is still signified. In the poem "All of My Friends Are Dead" Andrews writes:

All of my friends are dead-too bad for them; which was in practice little more than banging one inadequate category against another. Step on the advice of his children. Communication. (I Don't Have Any Paper 9)

Certainly, it does seem somewhat ridiculous to say "too bad for them" after referencing one's dead friends. One could even argue that the unexpected shift contains a darkly humorous quality. But what exactly is being signified? Their death is little more than an inadequate category, as there is no pattern of repetition with which to create narrative coherency. Whose children are we discussing, 
and what advice were they given? Communication is literally broken via enjambment: "Communi-cation." At best, one can claim that this is a parody of syntax itself.

Finally, the term "genres of billingsgate" refers to "curses, oaths, [and] popular blazons" (Bakhtin 5). I Don't Have Any Paper certainly does include curses, oaths, and popular blazons. The title of "Animal Dicks in Bed" employs a curse in and of itself, as the word "dicks," used in reference to the genitals, is commonly accepted as a profane term. As I noted above, in it Andrews writes "Arsenio, fuck me!" (18). Such terms, coupled with a "Bidirectional orgasm" (19), seem carnivalesque and grotesque in a more classic sense of the terms. Here we can see the sort of focus on the "lower stratum of the body, the life of the belly and the reproductive organs" (Bakhtin 21) that I made note of earlier in this article. This phenomenon is not specific to "Animal Dicks in Bed." It is, in fact, quite common in the compilation I Don't Have Any Paper. One need only scan the other titles of the poems in the compilation to prove as much. For example: "Education Helps me Squirt," "Semen Donor," "Toiling Virgin Midgets," and so on and so forth. While this explicit use of the carnivalesque and grotesque is interesting, I am not suggesting that it is particularly important to the similarity I have been discussing. I could make the argument of this article even if such an aesthetic was not present, and not one single point I have made up until this moment referenced such an aesthetic in $I$ Don't Have Any Paper to prove my point.

The particular similarity to the grotesque and the carnivalesque that I am elucidating stems from the way these texts become ritual spectacles by forcing people to interactively engage in the process of making meaning. The language of these texts acts as a parody of normative language. The physical object of language, its words, and their groupings, become "grandiose, exaggerated, immeasurable" (Bakhtin 19) grotesque bodies. It is not what is being referenced that is necessarily carnivalesque. The texts do not have to use signifiers to reference the signified of the grotesque 
body for this similarity to exist. To avoid the confusion created by calling such a text carnivalesque, one must be sure to categorize the type of carnivalesque found in the text as a linguistic carnivalesque. The linguistic carnivalesque is related to the carnivalesque described by Bakhtin, but it does not require the use of grotesque realism. Instead, it makes use of grotesque syntax, of undetermined signifiers. I Don't Have Any Paper is a ritual spectacle upon the marketplace of language, and in that linguistic carnivalesque the body of a poem is ruptured by the abjection of grotesque syntax. 0

\section{Works Cited}

Andrews, Bruce. I Don't Have Any Paper So Shut Up (or, Social Romanticism). Los Angeles: Sun \& Moon Press, 1992. Print.

Andrews, Bruce. Paradise \& Method: Poetics \& Praxis. Evanston: Northwestern UP, 1996. Print.

Bakhtin, Mikhail. Rabelais and His World. Trans. Hélène Iswolsky. Bloomington: Indiana UP, 1984. Print.

Barthes, Roland. "The Death of the Author." Contemporary Critical Theory. Ed. Dan Latimer. Harcourt Brace Jonanovich, 1989. 54-59. Print.

Evans, Fred. "Lyotard, Bakhtin, and Radical Heterogeneity."

Lyotard: Philosophy, Politics, and the Sublime. Ed. Hugh J.

Silverman. New York: Routledge, 2002. 61-74. Print.

Ma, Ming-Quian. Poetry as Re-Reading. Evanston: Northwestern UP, 2008. Print.

McCaffery, Steve. North of Intention: Critical Writings 1973-1986. New York: Roof Books, 2000. Print.

Perloff, Marjorie. Poetry On \& Off the Page. Evanston: Northwestern UP, 1998. Print. 
Porush, David. The Soft Machine: Cybernetic Fiction. New York: Methuen, 1985. Print.

Shetley, Vernon. After the Death of Poetry: Poet and Audience in Contemporary America. Durham: Duke UP, 1993. Print.

Suvin, Darko. "Defining the Literary Genre of Utopia: Some Historical Semantics, Some Genology, A Proposal, and a Plea." Metamorphoses of Science Fiction: On the Poetics and history of a Literary Genre. New Haven: Yale UP, 1979. 37-62. Print.

Wiener, Norbert. Human Use of Human Beings: Cybernetics and Society. Boston: Da Capo Press, 1954. Print.

Wrighton, John. Ethics and Politics in Modern American Poetry. New York: Routledge, 2010. Print.

David Milman's interests revolve around the fields of epistemology, ontology, cybernetics, and contemporary fiction, but every so often he finds himself distracted by various forms of poetry and the works of Shakespeare. David is currently working on earning his PhD, under the supervision of Associate Professor Allen Weiss, at York University. He earned a Master of Arts degree in English Literature in 2010, after writing a Major Research Project under the supervision of Associate Professor Arthur Redding. David received his Bachelor of Arts Honours degree in English Literature in 2008. 